\title{
Using the method of electrical imaging for obtaining the modulus of elasticity in open cast mining
}

\author{
Pavel Zuev ${ }^{1 *}$, Andrey Vedernikov ${ }^{1}$ and Danila Grigoriev ${ }^{1}$ \\ ${ }^{1}$ The Institute of Mining of the Ural branch of the Russian Academy of Sciences, 620075, \\ Ekaterinburg, Russia.
}

\begin{abstract}
The article presents a description of the methodology for obtaining data on the physical properties of rocks that compose the sides of the open pit for technological optimization of drilling and blasting operations. The methodology is based on field measurements and calculation methods for determining the hardness of rocks at a chrysotile asbestos deposit, which is being mined by an open pit. The physical properties are obtained by comparing a priori geological data with the values of electrical resistivity and the velocities of elastic waves in the rocks. Based on these data, the values of the Young's modulus are calculated, which characterizes the strength of the rocks composing the array.
\end{abstract}

\section{Introduction}

When conducting drilling and blasting operations in quarries, you should always raise the question of optimizing this process to avoid the occurrence of pieces of rock mass of substandard sizes. While maintaining consistency in the process of drilling and loading the grid of wells, the degree of disturbance of the massif primarily affects the output of oversized pieces. The most reliable way to determine the state of the array is, of course, core sampling, but this procedure is not rational during regular blasting operations due to significant slowdown and increase in cost of work. The most optimal, in our opinion, is a preliminary study of the rock mass using geophysical methods. Their accuracy is usually sufficient in solving the voiced problem, and efficiency is ensured by implementing research in advance.

This article describes the experience of applying the methodology for obtaining the physical parameters of a rock mass (Poisson's ratio, Young's modulus, etc.) from the results of geophysical studies. The idea of the research is to test some geophysical methods for determining the structural-tectonic and strength properties of the rocks and to select the most informative and productive equipment for diagnostics of the rock blocks being prepared for blasting when planning drilling and blasting operations. Geophysical methods are based on identifying areas with sharply differing physical fields and structural disturbances [1].

* Corresponding author: zuev@igduran.ru 


\section{Object of research}

The research was carried out in an open pit mining of asbestos. The field is located in the Republic of Kazakhstan, in the region of the city of Zhitikara (formerly Dzhetygara), opened in 1916, and has been developed since 1961. It is the only asbestos deposit in Kazakhstan.

Chrysotile asbestos, or "white asbestos", belongs to a group of natural minerals that carry the commercial name "asbestos". It is part of the serpentine group and structurally belongs to layered silicates. Chrysotile-asbestos is a magnesium hydrosilicate found in nature as a crystal consisting of hollow tubes-fibrils with a diameter of $20-30 \mathrm{~nm}$ and a length of up to $2-3 \mathrm{~cm}$. The mineral is able to split into the thinnest chrysotile fibers up to 0.5 microns thick. Chrysotile-asbestos has an extensive set of properties, which dictates its wide scope of application. The chrysotile industry produces more than 3000 items of various industrial products [2].

The specificity of the Dzhetygarinskoye field and the pit in its development from the standpoint of geomechanical problems is determined, first of all, by the location of the field within the deep regional fault. The massif of ultrabasic rocks, including asbestos-bearing fields, is elongated within the fault in the meridional direction by more than $18 \mathrm{~km}$ with an average width of $3 \mathrm{~km}$ and a maximum width of $6 \mathrm{~km}$. The massif is divided into southern, central and northern parts by granitoids intrusions.

The fact that the deposit is associated with regional and intra-fault tectonics determines the high geodynamic activity of the rock mass. This activity is accompanied by an unusual and variable stress-strain state of the rock mass over time, which creates difficulties in ensuring the stability of the sides of the quarry and optimal performance of drilling and blasting operations.

Previously, the results of earlier studies were analyzed. It was found that in the structure of the rock massif of the Dzhetygarinskoye deposit, there is a differentiation by physical and mechanical parameters. In the sides of the quarry there are zones of decompression, areas of shale, zones with increased fracturing of rocks. In most cases, these structural inhomogeneities are caused by tectonic disturbances. The mining industry of this region of Northern Kazakhstan has always cooperated and continues to cooperate with industrial enterprises and scientific organizations in the Urals, Russia. As part of the established cooperation with the Institute of mining of the Ural branch of the Russian Academy of Sciences, researchers from the laboratory of technologies for disaster risk reduction conducted experimental work to select a method for studying the strength of rocks of an open-pit deposit to ensure the rational management of drilling and blasting operations.

\section{Methodology}

The first geophysical method tested for the study of the sides of the quarry was the method of electrical resistivity tomography. It includes measurements of electrical resistances and induced polarization values. The electric field observed on the earth's surface when an electric current passes through grounded electrodes depends on the distribution of resistivity in a certain area of the cut near the installation. Measurements are carried out using the same power and measuring electrodes, fixed on the observation profile. For the study of geoelectric sections that differ significantly from horizontally layered ones, the use of electric imaging is a prerequisite for reliable interpretation. Such a complex structure is usually characteristic of ore zones and zones of tectonic disturbances, landslides, bulk and artificial soils in urban areas, permafrost, with a steep fall of layers and in the presence of karst. Interpretation of electrical resistivity tomography data is performed for twodimensional and three-dimensional models. The resolution (i.e., the number of details of a 
geoelectric section that are stable in an electric field) and, accordingly, the quality of interpretation of electrical resistivity tomography data is closely related to the number and density of measurements on a single profile, their number usually reaches the first thousand at the length of profiles of the order of 100-200 meters [3]. In our case, a two-dimensional model was built based on the measurement results, since the distance between the profiles did not exceed 5 meters and there was no need to create a three-dimensional model. Each profile consists of 1-2 arrays, 32-64 electrodes each. The step between the electrodes is selected from 1 to $5 \mathrm{~m}$ respectively the total length of one placement is from 31 to 155 meters. From the first to the last electrode, the spread is connected by a cable. The measurements are carried out in a semi-automatic mode according to the protocols previously loaded into the switching equipment, which describe the procedure for connecting the power and measuring electrodes on the electrometric cable. Depending on the relative position of the receiving and supplying electrodes, different types of electrical prospecting installations are distinguished. In this work, we used an axial dipole setup, a Schlumberger setup, and a direct three-electrode AMN setup. Each has its pros and cons, and the choice of a set of specific setups is carried out according to the expected conditions of the rock mass.

For a reliable interpretation of the electric imaging data, a priori data provided by the deposit's geological service were used: a geological description of the areas with an indication of rocks, their fracturing, shaleiness, iron content, ore content, data on the strength of rocks and water outflows. Based on the results of interpretation of resistance values and induced polarization values measured in Ohms, geoelectric sections of the quarry walls are constructed (figure 1). Thus, the composition of the pit wall massif is determined, in most cases each rock within the study area has its own specific electrical resistance, respectively, the geological composition of the wall and the strength of the rocks enclosing it are determined. Resistances and rocks are correlated according to available drilling data.

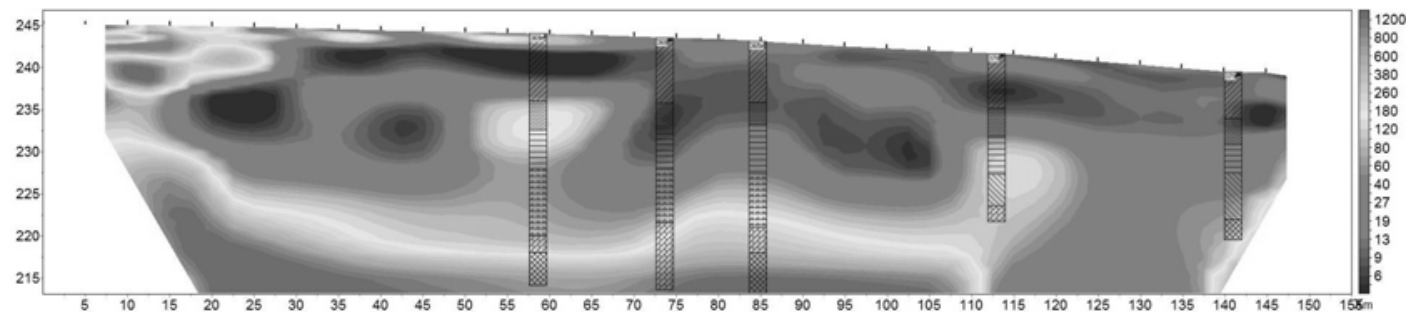

Fig.1. An example of a geoelectric section: the distribution of resistivity $(\mathrm{Ohm} \cdot \mathrm{m})$ in the massif, shown in a gradient.

The second method tested in the study area was the method of seismic exploration on refracted waves [4]. Here the similarity with the first method appears - seismic receivers are also placed along the profile, connected by a cable. Registration of elastic waves refracting in the layers of the earth's crust takes place. The point of seismic vibrations start is set on the surface of the quarry side. As a source of seismic waves are used a cylindrical metal weight of about $80 \mathrm{~kg}$, dropped in free fall from a height of $4 \mathrm{~m}$ above the surface of the measurement point on a special metal plate or a sledgehammer with a mass of the working part of $6 \mathrm{~kg}$. The transit times of primary and shear waves through the investigated massif are measured. As a result of calculations of wave velocities and their interpretation, seismic sections are constructed. Similarly, if a priori information is available, the obtained velocities are correlated with the available rocks in the section.

Then, using the speed values, the Poisson's ratio is calculated for all points of the speed section using the well-known formula: 


$$
\mu=\frac{0,5-R^{2}}{1-R^{2}}
$$

where $\mathrm{R}$ - shear wave velocity to primary wave velocity ratio. The resulting Poisson's ratio is an indicator of the deformability of the soil, which characterizes the ratio of the transverse and longitudinal deformations of the soil, and is necessary to calculate the dynamic Young's modulus.

For each point of the section, according to a priori data and based on the electrical resistance and elastic wave velocities obtained from field observations, the density of rocks is determined. The used method of seismic survey on refracted waves, due to its peculiarities, does not fully reflect abrupt changes in the properties of rocks in the massif therefore priority was given to electrical imaging survey. According to the well-known formula, Young's modulus is further calculated:

$$
E_{\text {д }}=c_{\text {пр }}^{2} \rho \frac{(1+\mu)(1-2 \mu)}{(1-\mu)}
$$

where $\mu$ - the Poisson's ratio, $\rho$ - rock density, $\mathrm{c}_{\text {пр }}$ - primary wave velocity.

Based on the results of these calculations, two-dimensional sections are constructed with the distribution of the values of the young's modulus of elasticity in the array, this indicator is correlated with the values of the rock strength and we get the desired result (figure 2). Further, information from these sections is transmitted to prepare changes in blast-hole drilling for specific areas.

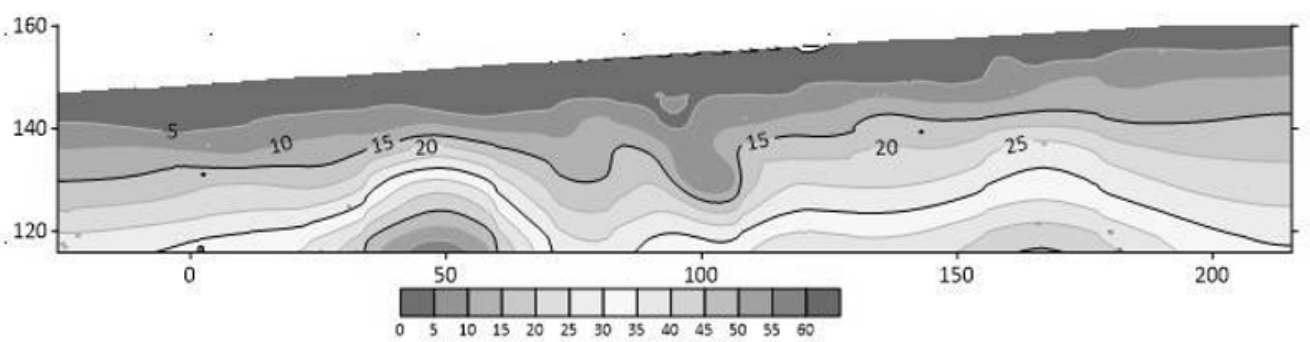

Fig. 2. An example of a section with the distribution of Young's modulus of elasticity (MPa) values in the studied massif, displayed in a gradient.

\section{Results and conclusions}

It is worth noting the successful integrated use of geophysical methods aimed at determining and further applying the physical properties of the rocks composing the rock massif. In our study, the results of the first methods were applied in obtaining the results of the second.

Of the disadvantages of the method used, it can be noted that the selected methods cannot be called express methods, mainly due to the time spent on processing and interpretation. The use of more operational methods is quite acceptable, if they provide the necessary level of detail of the resulting section. Improving measurement and interpretation techniques will have a positive impact on the result, as well as the joint application of methods.

As a result, data on the hardness of rocks composing the sides of the open pit were successfully used to optimize drilling and blasting operations. In particular, the mass of the exploding charge and the dimension of the charge grid were adjusted [5]. According to preliminary reviews from the enterprise, the use of this technique has significantly 
improved the situation with the appearance of oversized pieces of rock during the blasting of the massif. This had a positive impact on the economic efficiency of chrysotile-asbestos mining.

The studies were carried out in accordance with the state task No. $0405-2019-0007$. Topic 3.

\section{References}

1. RSN 66-87. Engineering surveys for construction. Technical requirements for the production of geophysical works. Seismic exploration

2. What is chrysotile? https://chrysotile.ru/page/what-is-chrysotile/

3. A.A. Bobachev, Electrical exploration: manual on electrical exploration practice for students of geophysical specialties. Volume II small-depth electrical survey. Ed. $2^{\text {nd }}$ (Moscow, 2013)

4. A.S. Vedernikov, D.V. Grigoriev, P.I. Zuev, XV Urals geophysical school. Ekaterinburg - 2016, 056-060 (2016)

5. Kornilkov S.V., Stenin Y.V., Starikov A.D., Calculation of drilling and blasting parameters in borehole blasting at quarries: a tutorial (ISBN 5-230-25442-4, Ekaterinburg, 1997) 